\title{
Preparation and Characterization of Nickel-Doped Zinc Sulphide Thin Films for Solar Cell Applications
}

\author{
Ayse Kucukarslan \\ Department of Physics, Canakkale Onsekiz Mart University, \\ Terzioglu Campus, Canakkale, Turkey \\ E-mail: akucukarslan@comu.edu.tr \\ Barbaros Demirselcuk \\ Vocational School of Technical Sciences, Canakkale Onsekiz Mart University, \\ Terzioglu Campus, Canakkale, Turkey \\ E-mail: bdemirselcuk@comu.edu.tr \\ Esra Kus \\ Graduate School of Natural and Applied Sciences, Uludag University, \\ Gorukle Campus, Bursa, Turkey \\ E-mail: EsraaKus@hotmail.com \\ Idris Akyuz \\ Department of Physics, Eskisehir Osmangazi University, \\ Meselik Campus, Eskişehir, Turkey \\ E-mail: iakyuz@ogu.edu.tr \\ Vildan Bilgin (Corresponding author) \\ Department of Physics, Canakkale Onsekiz Mart University, \\ Terzioglu Campus, Canakkale, Turkey \\ E-mail: vbilgin@comu.edu.tr
}

\begin{abstract}
"The research is financed by the Canakkale Onsekiz Mart University Scientific Research Projects Committee
\end{abstract} under the Project Number FBA-2019-3039."

\begin{abstract}
This study presents the production of pure and different amounts of Ni-doped (4, 8, 12\%) ZnS films on microscope glass substrate at $400 \pm 5^{\circ} \mathrm{C}$ substrate temperature with Ultrasonic Spray Pyrolysis Technique and the effect of $\mathrm{Ni}$ doping on some physical properties of pure films. X-ray diffractometer (XRD), UV-Vis spectrophotometer, two-probe method and atomic force microscope (AFM) were used to analyze the structural, optical, electrical and surface properties of all films, respectively. XRD patterns contains broad peaks showing a low crystallinity level for the films. Ni doping caused $\mathrm{ZnS}$ films to have high absorbance values through the visible spectrum. Optical band gap energy values of $\mathrm{ZnS}: \mathrm{Ni}$ thin films were determined to be between 3.71-3.96 eV. Two-probe measurements revealed that the electrical conductivity values of $\mathrm{ZnS}$ films increased significantly depending on the Ni doping. AFM results showed that the films have an almost homogeneous distribution with a rough surface. No significant change was observed for the surface properties of the films due to the Ni doping. As a result of all analyzes; it was seen that $\mathrm{Ni}$ doping has an important effect on the optical and electrical properties of $\mathrm{ZnS}$ films, without modifying the crystalline structure or surface texture.
\end{abstract}

Keywords: Zinc sulphide films; Nickel doping; Ultrasonic spray pyrolysis; Optical and electrical properties; XRD; AFM.

DOI: $10.7176 /$ JSTR/7-04-03

20 | P a g e

www.iiste.org 


\section{Introduction}

Semiconductor thin film materials obtained from II-VI group elements can be used as buffer/window layer for solar cells (Kaushalya et al., 2018; Hernández-Fenollosa et al., 2008). Zinc sulfide (ZnS) is one of the first semiconductors discovered (Fang et al., 2011). ZnS has been studied extensively in the literature and its usage is increasing day by day, especially in photovoltaic solar cells applications (Echendu et al., 2014; Echendu and Dharmadasa, 2015; Akhtar et al., 2015) and various photonic devices (Bashar et al., 2020; Echendu and Dharmadasa, 2013; Al-Diabat et al., 2019).

Zinc sulfide $(\mathrm{ZnS})$ is one of the II-VI semiconductors with n- or p-type conductivity, which attracts the attention of many researchers (Echendu et al., 2013; Cheng et al., 2003; Wood-Robinson et al., 2016). The fact that this material has a wide optical band gap (3.40-3.98 eV) enables it to transmit most of the electromagnetic spectrum to be used in solar cell applications (Yang, Li \& Zeng, 2019; Dehghani, Shadrokh \& Nadafan, 2017; Poornaprakash et al., 2015). Also, with its higher optical band gap as a window material in solar cells $\mathrm{ZnS}$ is more convenient as it allows high transmittance in the short wavelength region $(350-550 \mathrm{~nm})$ compared to $\mathrm{CdS}$ which has a lower optical band gap of $2.42 \mathrm{eV}$ (Hurma, 2019; Wei et al., 2013). In addition to having low reflectivity $\mathrm{ZnS}$ has a refractive index $(n)$ of 2.30-2.40, which makes it possible to be applied as an anti-reflective coating in thin-film solar cells (Deepa, Sunil Anantha \& Jampana, 2017; Tec-Yam et al., 2012; Axelevitch and Apter, 2016). When $\mathrm{ZnS}$ semiconductor is used instead of $\mathrm{CdS}$, it has been observed that CIGS thin film solar cells show an increased conversion efficiency by $18.6 \%$ at short wavelengths (Shin et al., 2011; Doha et al., 2015). The fact that $\mathrm{ZnS}$ semiconductor can be produced as n-type and p-type increases the motivation of researches on the potential use of ZnS in CdTe, CIGS and CZTS based thin film solar cells (Doha et al., 2015; Kong, Deng \& Chen, 2017). Using wide band gap materials such as ZnS instead of CdS, which is the most preferred semiconductor in solar cell structure, can further improve conversion efficiency (Tobbeche et al., 2019; Derbali et al., 2018; Chelvanathan et al., 2015). In addition, it is preferable to use $\mathrm{ZnS}$ semiconductor thin films as a window layer in solar cells due to their non-toxicity and wide band gap (Benyahia, Benhaya \& Aida, 2015; Wang et al., 2017; Hernández-Castillo et al., 2017).

Type of the doping element and its ratio affect the properties of a material. ZnS films doped with metal ions have improved optical properties (Karar, Singh \& Mahta, 2004; Zhao et al., 2017). There are various studies on the photoluminescence properties of $\mathrm{ZnS}$ nanostructures doped with various metals such as $\mathrm{Cu}, \mathrm{Mn}, \mathrm{Co}, \mathrm{Fe}, \mathrm{Ni}$ and other transition elements (Ghorai et al., 2019; Bouznit et al., 2014; Kumar et al., 2015; Talantikite-Touatia et al., 2017). These doping processes provide photoluminescence bands in different regions such as in orange region by $\mathrm{Mn}$, green region by $\mathrm{Eu}$ and blue region by $\mathrm{Cu}$ doping (Ebrahimi, Yarmand \& Naderi 2019; Wei et al., 2018; Mishra, Ojha \& Khare 2018).

$\mathrm{ZnS}$ thin films were grown by many researchers using different techniques such as chemical bath deposition (CBD), successive ionic layer adsorption and reaction (SILAR), sol-gel, RF magnetron sputtering, pulsed laser deposition and ultrasonic spray pyrolysis (Yang, Li \& Zeng, 2019; Akhtar et al., 2017; Patel et al., 2010; Alnama, Abdallah \& Kanaan, 2016; Hennayaka and Lee, 2013). In this study, Ultrasonic Spray Pyrolysis method was used to coat ZnS thin films on glass substrates using Zn (Zinc), $\mathrm{S}$ (Sulfur) and Ni (Nickel) sources. Ultrasonic Spray Pyrolysis method has been preferred due to its advantages such as its simplicity, allowing for internal doping, low cost, ability to be performed at the desired temperature, having less chemical waste products and wide use in optoelectronic applications (Offor et al., 2020; Hurma, 2018).

Our aim in this study is to produce $\mathrm{ZnS}$ :Ni thin films by an economic way and investigate the effect of $\mathrm{Ni}$ doping on physical properties in detail. With respect to this aim, undoped and Ni doped ZnS films were grown on the glass substrates by using a low cost USP technique and structural, optical, electrical and morphological properties of $\mathrm{Ni}$ doped films were investigated.

\section{Experimental Details}

The undoped and Ni-doped $\mathrm{ZnS}$ films were grown smoothly on microscope glass substrates using the Ultrasonic Spray Pyrolysis System (CAVES-tek, AVE-USP-300, Turkey). Firstly, the microscope glass substrates were cleaned using an ultrasonic bath in deionized water for 10 minutes and allowed to dry. Subsequently, aqueous solutions of $0.05 \mathrm{M} \mathrm{ZnCl}_{2}$ as the $\mathrm{Zn}$ source, $0.075 \mathrm{M} \mathrm{CH}_{4} \mathrm{~N}_{2} \mathrm{~S}$ as the $\mathrm{S}$ source and $0.1 \mathrm{M} \mathrm{NiCl}_{2} \cdot 6 \mathrm{H}_{2} \mathrm{O}$ as the $\mathrm{Ni}$ source, were prepared. As given in Table 1, a total of $150 \mathrm{ml}$ of initial spraying solution was obtained by mixing the appropriate proportions of solutions such that the volume percentage of the $\mathrm{Ni}$ source in the spraying solution to be $0,4,8$ and $12 \%$. The spraying process was carried out for 30 minutes at a substrate temperature of $400^{\circ} \mathrm{C}$, which was controlled by an iron-

21 | $P$ a g e

www.iiste.org 
constantan thermocouple, and at a constant flow rate of $5 \mathrm{ml} \cdot \mathrm{min}^{-1}$. An ultrasonic atomizer with 100 $\mathrm{kHz}$ and $8 \mathrm{~W}$ output power was used as the spraying head and compressed air $\left(10^{5} \mathrm{~Pa}\right)$ was used as carrier gas.

Firstly, a spectroscopic ellipsometer (OPT S-9000, 250-2100 nm measurement range) was adopted to measure the thicknesses of ZnS:Ni films. It was observed that the thicknesses of films listed in Table 1 varied between 67-202 nm and increased with Ni doping. The PANalytical Empyrean diffractometer with copper target $(\lambda=1.54060 \AA)$ was employed to obtain X-ray diffraction (XRD) patterns and perform structural analysis of the films. In order to examine the optical properties of $\mathrm{ZnS}: \mathrm{Ni}$ thin films and to analyze the effect of $\mathrm{Ni}$ doping, the transmittance and absorbance spectra were taken in the 300$900 \mathrm{~nm}$ wavelength range using Shimadzu-SolidSpec-2550 UV-Vis spectrophotometer. Two-probe and hot-probe techniques were adopted to determine the electrical conductivity values and majority carrier types of the films, respectively. Current-voltage (I-V) measurements of the films were taken at room temperature (RT) in dark using Keithley 2400 source meter. The variation of surface morphologies and roughness values of the films, depending on the $\mathrm{Ni}$ doping, was analyzed using atomic force microscopy (AFM, Park Systems XE-100).

Table 1. Volume of sources used for spraying solution and the thickness values of the $\mathrm{ZnS}$ :Ni films.

\begin{tabular}{|l|c|c|c|c|c|}
\hline \multicolumn{1}{|c|}{ Material } & $\mathrm{ZnCl}_{2}(\mathrm{ml})$ & $\mathrm{CH}_{4} \mathrm{~N}_{2} \mathrm{~S}(\mathrm{ml})$ & $\mathrm{NiCl}_{2} \cdot 6 \mathrm{H}_{2} \mathrm{O}(\mathrm{ml})$ & Total $(\mathrm{ml})$ & Thickness (nm) \\
\hline ZnS & 75 & 75 & - & & 67 \\
\cline { 1 - 4 } ZnS:Ni (4\%) & 72 & 72 & 6 & \multirow{2}{*}{150} & 101 \\
\cline { 1 - 4 } ZnS:Ni (8\%) & 69 & 69 & 12 & & 188 \\
\cline { 1 - 4 } ZnS:Ni (12\%) & 66 & 66 & 18 & & 202 \\
\hline
\end{tabular}

\section{Results and Discussions}

\subsection{Structural Analysis}

In order to examine the effect of $\mathrm{Ni}$ doping on the structural and phase composition of $\mathrm{ZnS}$ thin films, the diffraction patterns of the films were taken using X-ray diffractometer in the $20^{\circ}-80^{\circ}$ diffraction angle range and given in Figure 1. From these XRD patterns, it was determined that $\mathrm{ZnS}: \mathrm{Ni}$ thin films contains broad peaks that refers an amorphous structure and these low intensity diffraction peaks corresponds to the lattice planes of (002) and (110), which belong to the $\mathrm{ZnS}$ hexagonal wurtzite structure (JCPDS card no: 36-1450). No secondary phases related to either Zn, Ni or their oxides were observed. Diffraction peak positions $(2 \theta)$, interplanar spacing $(d)$, Miller indices $(h k l)$ and crystal systems are given in Table 2 and the values for all films are in agreement with the literature (WoodsRobinson et al., 2016; Hurma, 2019; Bouznit et al., 2014; Alnama, Abdallah \& Kanaan, 2016; Benama et al., 2020). However, it was seen from Fig 1 and Table 2 that there was no significant change in the structural properties of the films due to the Ni contribution.

In addition, the lattice constants ( $a=b$ and $c$ ) and volume of unit cell $(V)$ for all films were calculated using the formulas defined for hexagonal system (Zhao et al., 2017; Benamra et al., 2020),

$$
\begin{aligned}
& \frac{1}{d^{2}}=\frac{4}{3}\left(\frac{h^{2}+h k+k^{2}}{a^{2}}\right)+\frac{l^{2}}{c^{2}} \\
& V=a^{2} c
\end{aligned}
$$

where $d$ is the interplanar spacing and $h, k$ and $l$ are the Miller indices. These values are given in Table 3 and in agreement with the values provided in the JCPDS card numbered 36-1450 for the ZnS hexagonal structure. 

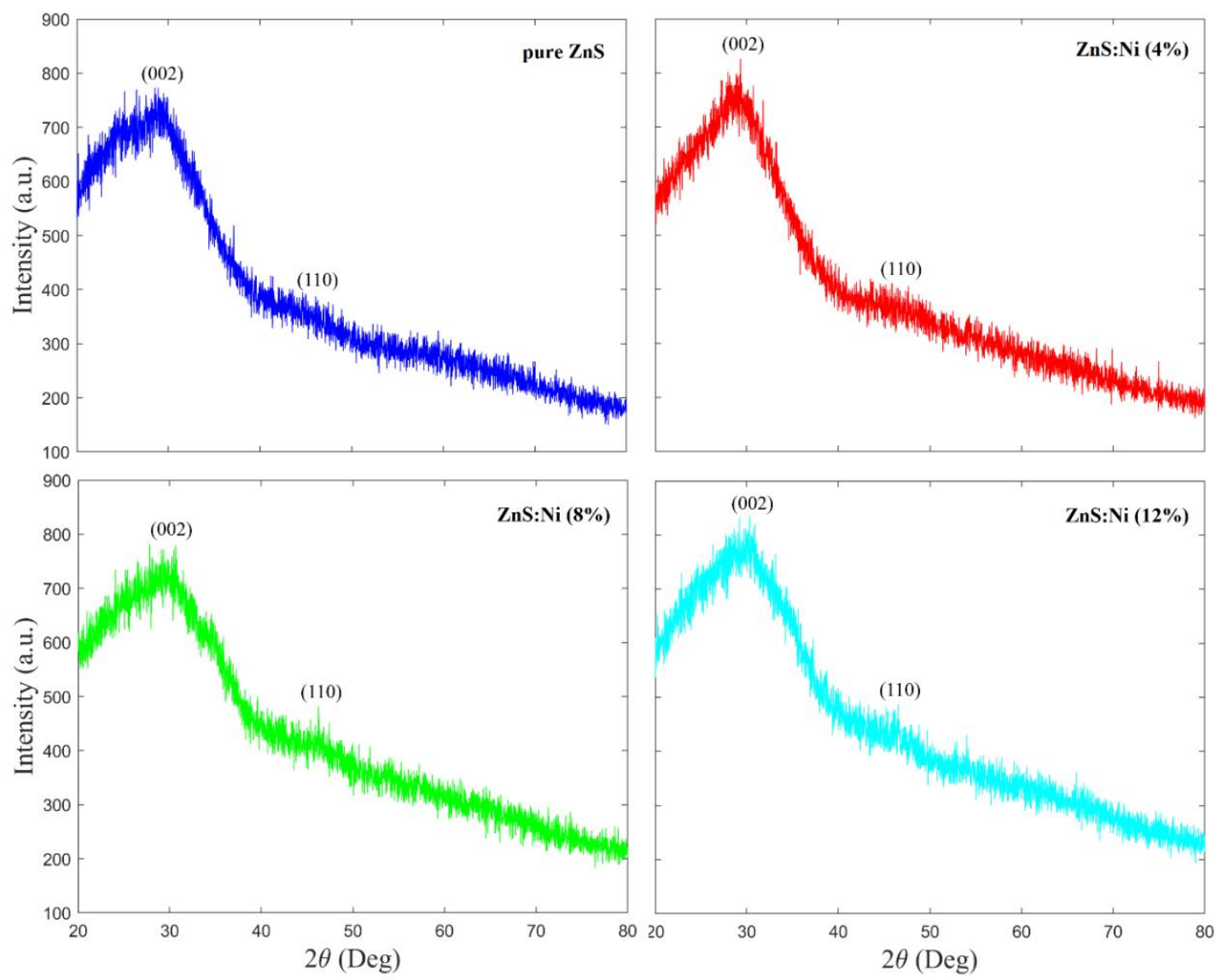

Figure 1. XRD patterns of pure and $\mathrm{Ni}$ doped $\mathrm{ZnS}$ thin films.

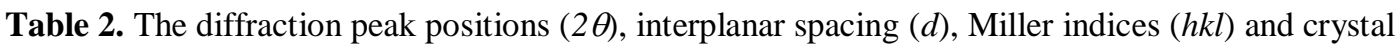
systems for $\mathrm{ZnS}: \mathrm{Ni}$ thin films.

\begin{tabular}{|l|c|c|c|c|}
\hline \multicolumn{1}{|c|}{ Material } & $2 \theta\left(^{\circ}\right)$ & $d(\AA)$ & $(h k l)$ & \multirow{2}{*}{ Crystal system } \\
\hline \multirow{2}{*}{ ZnS } & 28.89 & 3.088 & $(002)$ & \multirow{2}{*}{ ZnS hexagonal } \\
\cline { 2 - 4 } & 47.64 & 1.907 & $(110)$ & \\
\hline \multirow{2}{*}{ ZnS:Ni (4\%) } & 29.31 & 3.044 & $(002)$ & \multirow{2}{*}{ ZnS hexagonal } \\
\cline { 2 - 4 } & 47.63 & 1.907 & $(110)$ & \\
\hline \multirow{2}{*}{ ZnS:Ni (8\%) } & 30.65 & 2.914 & $(002)$ & \multirow{2}{*}{ ZnS hexagonal } \\
\cline { 2 - 4 } & 46.92 & 1.961 & $(110)$ & \multirow{2}{*}{ ZnS hexagonal } \\
\hline \multirow{2}{*}{ ZnS:Ni (12\%) } & 30.30 & 2.947 & $(002)$ & \multicolumn{2}{|c|}{} \\
\cline { 2 - 4 } & 46.50 & 1.951 & $(110)$ & \\
\hline
\end{tabular}


Table 3. The lattice constants $(a=b$ and $c$ ) and volume of unit cell $(V)$ for $\mathrm{ZnS}: \mathrm{Ni}$ thin films.

\begin{tabular}{|l|c|c|c|c|c|c|}
\hline \multirow{2}{*}{ Material } & \multicolumn{3}{|c|}{ Calculated } & \multicolumn{3}{c|}{ JCPDS cards } \\
\cline { 2 - 5 } & $V(\AA)^{3}$ & $a=b(\AA)$ & $c(\AA)$ & $V(\AA)^{3}$ & $a=b(\AA)$ & $c(\AA)$ \\
\hline ZnS & 77.85 & 3.814 & 6.176 & & & \\
\cline { 1 - 4 } ZnS:Ni (4\%) & 76.75 & 3.815 & 6.088 & \multirow{2}{*}{76.45} & 3.777 & 6.188 \\
\cline { 1 - 5 } ZnS:Ni (8\%) & 77.66 & 3.922 & 5.828 & & \\
\cline { 1 - 4 } ZnS:Ni (12\%) & 77.75 & 3.903 & 5.894 & & & \\
\hline
\end{tabular}

\subsection{Optical Analysis}

The transmittance and absorbance spectra required for detailed optical analysis of $\mathrm{ZnS}: \mathrm{Ni}$ thin films were taken in the range of 300-900 nm wavelength using a UV-Vis spectrophotometer and Figure 2a and Figure $2 b$ show these spectra, respectively. The first noticeable detail in these spectra is that the pure $\mathrm{ZnS}$ has transmittance value of approximately $40 \%$ in the visible region and there is a significant decrease in the transmittance values due to the Ni doping. This also means that the absorbance values of pure $\mathrm{ZnS}$ films increase with the increase in Ni amount in the structure. This means that Ni doping causes the $\mathrm{ZnS}$ films to be optically denser, as the absorbance is an indicator of optical density.

The fundamental absorption spectra were used to calculate the optical band gap energies of the films using Tauc expression given as follows (Bashar et al., 2020; Al-Diabat et al., 2019; Wei et al., 2013; Benamra et al., 2020).

$$
(\alpha h v)^{n}=A\left(h v-E_{g}\right)
$$

where $E_{g}$ is the optical band gap energy, $h v$ is the photon energy, $n=2$ for allowed direct transition and $A$ is a constant. Optical band gap energy $\left(E_{g}\right)$ values were calculated by extrapolating the linear part of the $(\alpha h v)^{2}$ versus $h v$ plots to $\alpha=0$ as given in Fig. 3. Optical band gap energy values of ZnS:Ni films listed in Table 4 change in the range of 3.71-3.96 eV and there is a small decrease in the optical band gap values with $\mathrm{Ni}$ doping. Optical band gap energies calculated for undoped and Ni doped ZnS films are in good agreement with other studies in the literature (Al-Diabat et al., 2019; Poornaprakash et al., 2015; Wei et al., 2013; Shin et al., 2011).
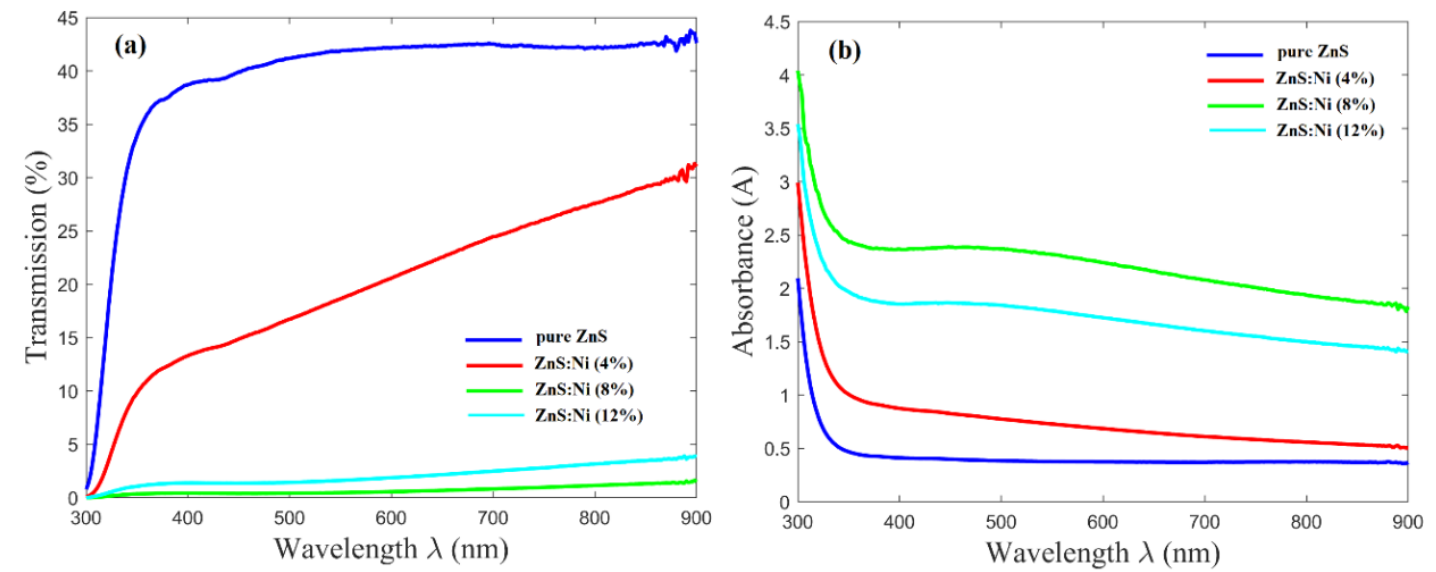

Figure 2. (a) Transmittance and (b) absorbance spectra of pure and Ni doped ZnS thin films. 
Table 4. The optical band gap energy $\left(E_{g}\right)$, electrical resistivity $(\rho)$, electrical conductivity $(\sigma)$ and average roughness $\left(R_{a}\right)$ values for $\mathrm{ZnS}: \mathrm{Ni}$ thin films.

\begin{tabular}{|l|c|l|l|c|}
\hline \multicolumn{1}{|c|}{ Material } & $\mathrm{E}_{\mathrm{g}}(\mathrm{eV})$ & $\rho(\Omega \mathrm{cm})$ & $\sigma(\Omega \mathrm{cm})^{-1}$ & $R_{a}(\mathrm{~nm})$ \\
\hline $\mathrm{ZnS}$ & 3.96 & $1.16 \times 10^{5}$ & $8.95 \times 10^{-6}$ & 63 \\
\hline $\mathrm{ZnS}: \mathrm{Ni}(4 \%)$ & 3.89 & $1.32 \times 10^{3}$ & $7.56 \times 10^{-4}$ & 45 \\
\hline ZnS:Ni $(8 \%)$ & 3.71 & $3.28 \times 10^{-1}$ & $3.05 \times 10^{0}$ & 61 \\
\hline ZnS:Ni (12\%) & 3.75 & $2.38 \times 10^{-2}$ & $4.21 \times 10^{+1}$ & 47 \\
\hline
\end{tabular}

\subsection{Electrical Analysis}

In order to determine the electrical conductivity values of $\mathrm{ZnS}: \mathrm{Ni}$ films, gold metal contacts were formed on the film surface in planar form by using mini plasma sputter (MTI Corporation, GSL1100X-SPC-16) system. Then, the current values of the films were measured at room temperature in dark conditions depending on the applied voltage in the range of $\pm 50 \mathrm{~V}$. However, hot-probe technique was adopted to determine the electrical conductivity types of the films and it was observed that all films have n-type electrical conductivity.

The electrical conductivities of $\mathrm{ZnS}: \mathrm{Ni}$ thin films were determined by two-probe technique in accordance with the following equation (Echendu et al., 2013; Derbali et al., 2018) and listed in Table 4.

$$
\frac{1}{\sigma}=\frac{\Delta V}{\Delta I}\left(\frac{d \times l}{L}\right)
$$

where $d$ is the thickness of film, $l$ is length of the metal contact and $L$ is the distance between two gold metal contacts. It can be seen from Table 4 that the electrical conductivity values of pure $\mathrm{ZnS}$ films are significantly increased depending on the increase in Ni contribution. As noted by Firdous, it is well known that $\mathrm{Ni}$ substitution in $\mathrm{ZnS}$ leads to carrier incorporation which in turn causes the conductivity to increase (Firdous, 2010).

\subsection{Morphological Analysis}

Morphological properties of $\mathrm{ZnS}$ thin films due to the $\mathrm{Ni}$ doping was examined using atomic force microscopy (AFM). Surface images of the films were obtained by scanning an area of $40 \times 40 \mu \mathrm{m}$ and the average roughness values $\left(R_{a}\right)$ of all films given in Table 4 were determined from these scanned regions. 3D surface images of $\mathrm{ZnS}$ :Ni thin films are given in Figure 4. It can be seen that the films have almost homogeneous surface distributions and no cracked structure was formed. The black and white areas draw attention on the AFM images. Black regions represent the presence of voids on the surfaces of the films while white regions represent the presence of agglomerations with different sizes. However, it is possible to say that the surface distributions and roughness values of the films do not change significantly depending on the Ni contribution.

\section{Conclusions}

In this study, the effect of $\mathrm{Ni}$ doping on some physical properties of zinc sulfide (ZnS) thin films deposited by USP technique was reported. XRD studies showed that the films have an almost amorphous structure with low intensity diffraction peaks. However, the secondary phases related to compounds of $\mathrm{Zn}$, Ni or their oxides was not detected. Optical studies showed that the absorbance values of the films increase with $\mathrm{Ni}$ doping. The optical band gap values of the films were calculated using the Tauc equation and it was determined that the films have a wide optical band gap energy of 3.71-3.96eV, which makes them desirable materials for thin film solar cell applications. Finally, the three-dimensional AFM images were taken to examine the surface morphology of the films. Films have an almost homogeneous surface distribution and there is not a dramatic change in surface roughness values of the with $\mathrm{Ni}$ doping. An important output of this study is the dramatic effect of Ni doping on electrical conductivity. With increased conductivity values, Ni doped $\mathrm{ZnS}$ films may be promising materials for use in photovoltaic applications.

25 | P a g e

www.iiste.org 
International Journal of Scientific and Technological Research ISSN 2422-8702 (Online), DOI: 10.7176/JSTR/7-04-03

Vol.7, No.4, 2021
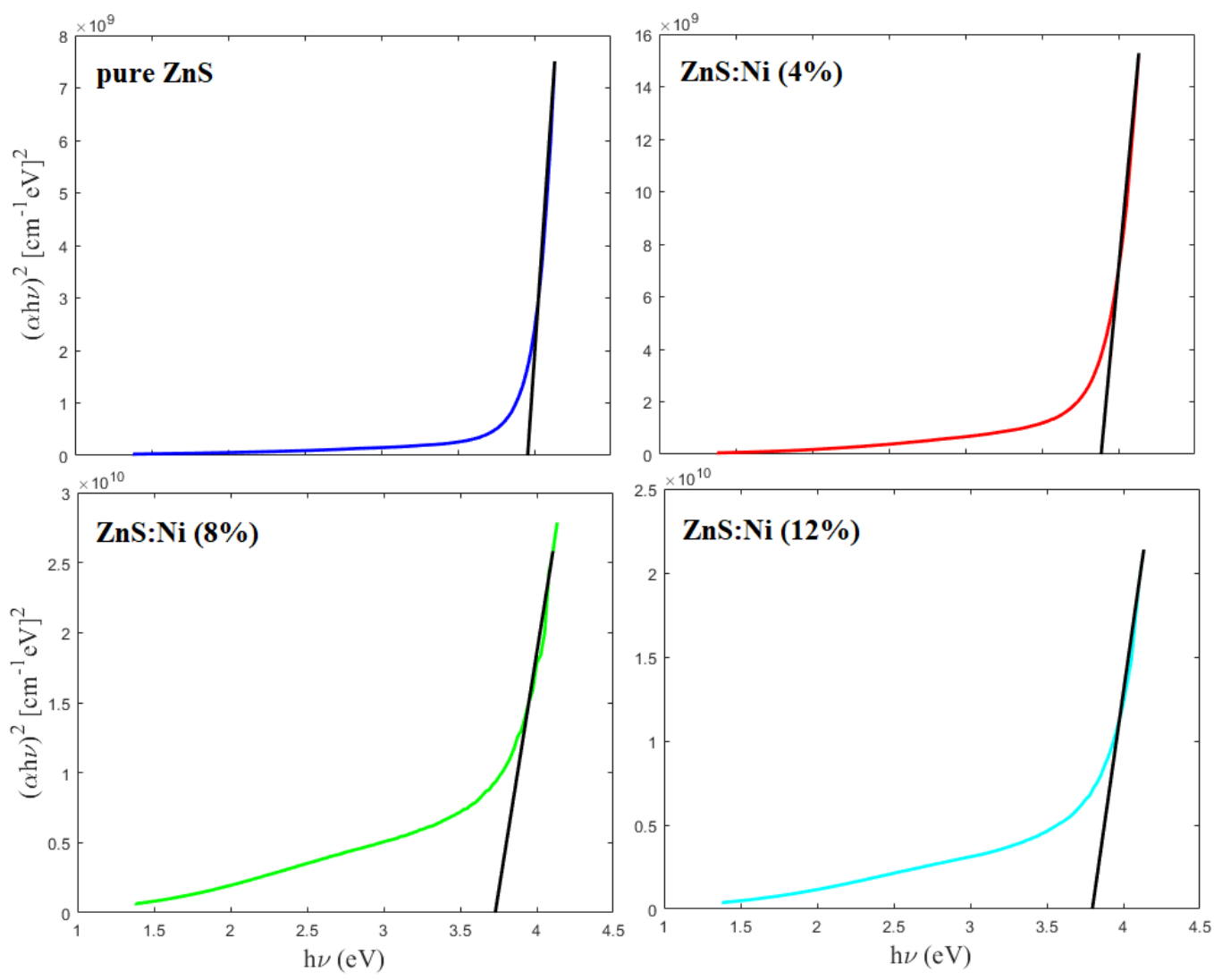

Figure 3. Tauc plots of pure and Ni doped $\mathrm{ZnS}$ thin films.
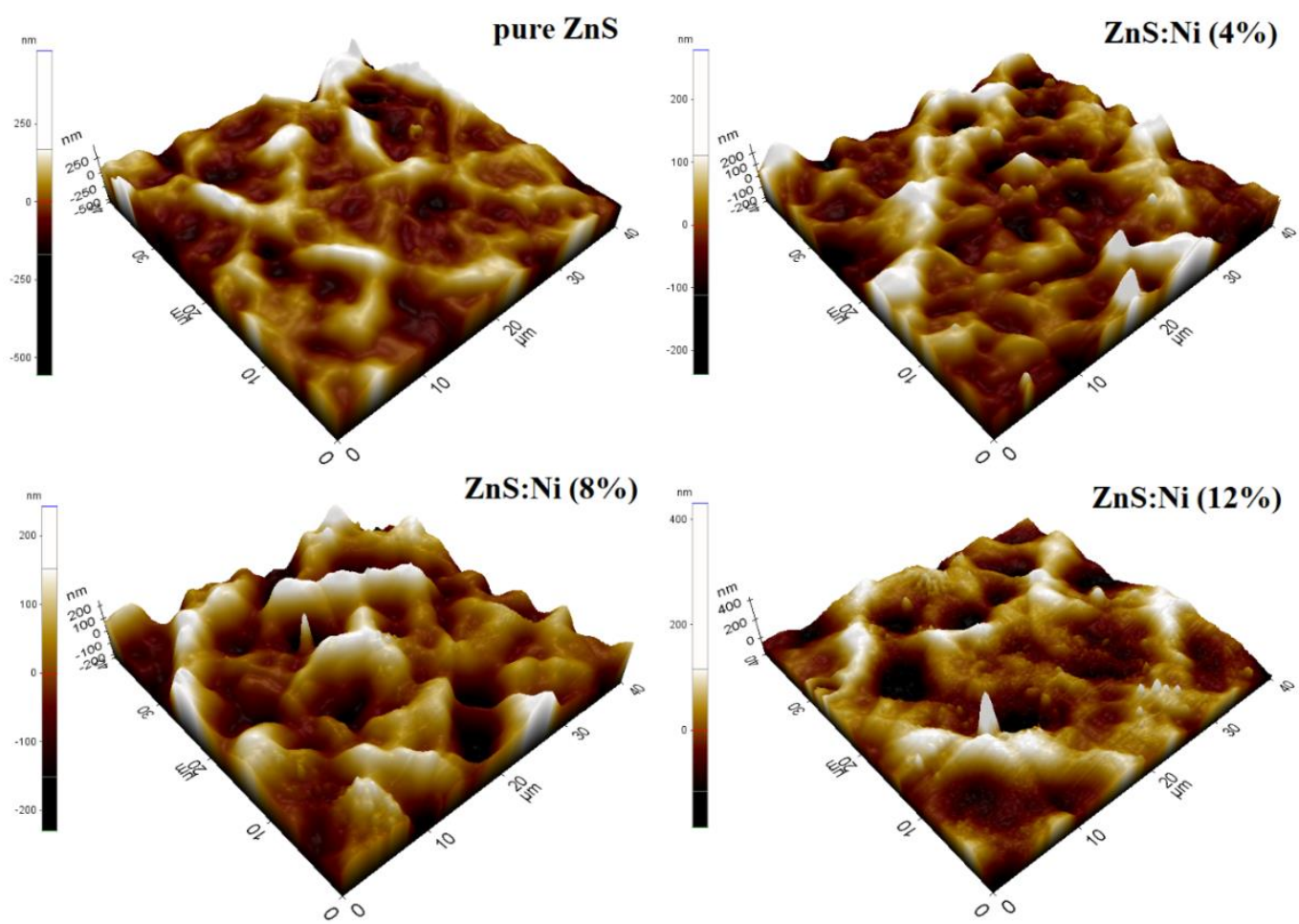

Figure 4. The AFM images of pure and Ni doped $\mathrm{ZnS}$ thin films. 


\section{References}

Akhtar, M.S. et al. (2015). Optimising conditions for the growth of nanocrystalline ZnS thin films from acidic chemical baths. Materials Science in Semiconductor Processing, 30, 292-297, http://dx.doi.org/10.1016/j.mssp.2014.10.019.

Akhtar, M.S. et al. (2017). Surfactant and template free synthesis of porous ZnS nanoparticles. Materials Chemistry and Physics, 189, 28-34, doi: 10.1016/j.matchemphys.2016.12.027.

Al-Diabat, A.M. et al. (2019). Growth of ZnS Thin Films using Chemical Spray Pyrolysis Technique. Materials Today: Proceedings, 17, 912-920, https://doi.org/ 10. 1016/ j.matpr.2019.06.390.

Alnama, K., Abdallah, B. \& Kanaan, S. (2016). Deposition of ZnS thin film by ultrasonic spray pyrolysis: effect of thickness on the crystallographic and electrical properties. Composite Interfaces, 24(5), 499-513, https://doi.org/10.1080/09276440.2017.1236538.

Axelevitch, A. and Apter, B. (2016). Preparation and study of doped ZnS thin films. Microelectronic Engineering, 170, 39-43, doi:10.1016/j.mee.2016.12.027.

Bashar, M. S. et al. (2020). Effect of rapid thermal annealing on structural and optical properties of $\mathrm{ZnS}$ thin flms fabricated by RF magnetron sputtering technique. Journal of Theoretical and Applied Physics, 14, 53-63, https://doi.org/10.1007/s40094-019-00361-5.

Benamra, H. et al. (2020). Physical properties of Al-doped ZnS thin films prepared by ultrasonic spray technique. Surfaces and Interfaces, 100645, https://doi.org/10.1016/j.surfin.2020.100645.

Benyahia, K., Benhaya, A. \& Aida, M. S. (2015). ZnS thin films deposition by thermal evaporation for photovoltaic applications. Journal of Semiconductors. 36(10), 103001, doi: 10.1088/16744926/36/10/103001.

Bouznit, Y. et al. (2014). Co-sprayed manganese doped zinc sulfide films. Journal of Luminescence, 151, 76-81, http://dx.doi.org/10.1016/j.jlumin.2014.02.006.

Chelvanathana, P. et al. (2015). Growth and characterization of RF-sputtered ZnS thin film deposited at various substrate temperatures for photovoltaic application. Applied Surface Science, 334, 138-144, http://dx.doi.org/10.1016/j.apsusc.2014.08.155.

Cheng, J. et al., (2003). Chemical bath deposition of crystalline $\mathrm{ZnS}$ thin films. Semiconductor Science Technology, 18, 676-679, doi:10.1088/0268-1242/18/7/313.

Deepa, K.G., Sunil Anantha, M. \& Jampana, N. (2017). Highly transparent ZnS buffer layer prepared by ultrasonic spray pyrolysis for photovoltaic applications. Journal of Analytical and Applied Pyrolysis, 126 (2-3), 188-193, http://dx.doi.org/10.1016/j.jaap.2017.06.009.

Dehghani, Z., Shadrokh, Z. \& Nadafan, M. (2017). The Effect of Magnetic Metal Doping on the Structural and The Third-Order Nonlinear Optical Properties of ZnS Nanoparticles. Optic, 131, 925-931, http://dx.doi.org/doi:10.1016/j.ijleo.2016.12.021.

Derbali, A. et al. (2018). Investigation of structural, optical and electrical properties of $\mathrm{ZnS}$ thin films prepared by ultrasonic spray technique for photovoltaic applications. Optik, 154, 286-293, https://doi.org/10.1016/j.ijleo.2017.10.034.

Doha, M.H. et al. (2015). Characterization of chemically deposited $\mathrm{ZnS}$ thin films on bare and conducting glass. Optik, 126(24), 5194-5199, http://dx.doi.org/10.1016/j.ijleo.2015.09.234. 
Ebrahimi, S., Yarmand, B. \& Naderi, N. (2019). Enhanced optoelectrical properties of Mn-doped ZnS films deposited by spray pyrolysis for ultraviolet detection applications. Thin Solid Films, 676, 31-41, https://doi.org/10.1016/j.tsf.2019.02.046.

Echendu, O.K. and Dharmadasa, I.M. (2013). Effects of Thickness and Annealing on Optoelectronic Properties of Electrodeposited $\mathrm{ZnS}$ Thin Films for Photonic Device Applications. Journal of Electronic Materials, 43(3), 791-801, dio: 10.1007/s11664-013-2943-y.

Echendu, O.K. and Dharmadasa, I.M. (2015). Graded-Bandgap Solar Cells Using All Electrodeposited ZnS, CdS and CdTe Thin-Films. Energies, 8(5), 4416-4435, doi: $10.3390 /$ en 8054416.

Echendu, O.K. et al. (2013). Characterization of n-Type and p-Type ZnS Thin Layers Grown by an Electrochemical Method. Journal of Electronic Materials, 42(4), 692-700, doi: 10.1007/s11664012-2393-y.

Echendu, O.K. et al. (2014). High short-circuit current density CdTe solar cell using allelectrodeposited semiconductors. Thin Solid Films, 556, 529-534, http://dx.doi.org/ 10.1016/j.tsf.2014.01.071.

Fang, X. et al. (2011). ZnS nanostructures: from synthesis to applications. Progress in Materials Science, 56(2), 175-287, doi:10.1016/j.pmatsci.2010.10.001.

Firdous, A. (2010). Optical and electrical properties of pure and Ni-modified ZnS nanocrystals. The European Physical Journal Applied Physics, 52(2), 20602, doi: 10.1051/epjap/2010144.

Ghorai, S. et al. (2019). Insights into local atomic structure of Fe alloyed ZnS nano crystals: Correlation with structural, optical, magnetic and photocatalyst properties. Journal of Alloys and Compounds, 805, 363-378, https://doi.org/10.1016/j.jallcom.2019.06.357.

Hennayaka, H.M.M.N. and Lee, H.S. (2013). Structural and optical properties of ZnS thin film grown by pulsed electrodeposition. Thin Solid Films, 548, 86-90, http://dx.doi. org/10.1016/j.tsf.2013.09.011.

Hernández-Castillo, R. et al. (2017). Study of ZnS/CdS structures for solar cells applications. Optik, 148, 95-100, http://dx.doi.org/10.1016/j.ijleo.2017.09.002.

Hernández-Fenollosa, M.A. et al. (2008). Role of precursors on morphology and optical properties of $\mathrm{ZnS}$ thin films prepared by chemical spray pyrolysis. Thin Solid Films, 516, 1622-1625, doi: 10.1016/j.tsf.2007.05.031.

Hurma, T. (2018). Structural and optical properties of nanocrystalline $\mathrm{ZnS}$ and $\mathrm{ZnS}: \mathrm{Al}$ films. Journal of Molecular Structure, 1161, 279-284, doi: 10.1016/j.molstruc.2018.02.070.

Hurma, T. (2019). The structural and optical properties of $\mathrm{ZnS}$ films obtained by spraying solutions at diffrent molarities. Materials Today: Proceedings, 18, 1875-1881, https://doi.org/ 10.1016/j.matpr.2019.06.676.

Karar, N., Singh, F. \& Mehta B.R. (2004). Structure and Photoluminescence Studies on ZnS:Mn Nanoparticles. Journal of Applied Physics, 95, 2, http://dx.doi.org/10.1063/1.1633347.

Kaushalya, et al. (2018). Thermal annealing evolution to physical properties of $\mathrm{ZnS}$ thin films as buffer layer for solar cell applications. Physica E: Low-dimensional Systems and Nanostructures, 101, 174-177, doi: 10.1016/j.physe.2018.04.006.

Kong, L., Deng, J. \& Chen, L. (2017). Structural and optical characterization of magnetron sputtered ZnS thin films annealed in different atmosphere. Chalcogenide Letters, 14(3), 87-96.

28 | P a g e

www.iiste.org 
Kumar, R.S. et al. (2015). Effect of nickel doping on structural and optical properties of ZnS nanoparticles. Superlattices and Microstructures, 86, 552-558, http://dx.doi. org/ 10.1016/j.spmi.2015.08.016.

Mishra, P., Ojha, K.S. \& Khare, A. (2018). Structural and optical study of copper-doped zinc sülfide nanoparticles. Journal of Applied Spectroscopy, 85(4), 743-748, doi: 10.1007/s10812-018-07145 .

Offor, P.O. et al. (2020). Effect of concentration of trisodium citrate complexing agent on spraysynthesized ZnS thin films. Materials Today: Proceedings, 36(2), 133-140, https:// doi.org/10.1016/j.matpr.2020.02.308.

Patel, S.P. et al. (2010). Grain growth and structural transformation in $\mathrm{ZnS}$ nanocrystalline thin films. Vacuum, 85(2), 307-311, doi:10.1016/j.vacuum.2010.06.011.

Poornaprakash, B. et al. (2015). Defect Induced Paramagnetism in Lightly Doped ZnS:Fe Nanoparticles. Physica E, 73, 63-68, http://dx.doi.org/10.1016/j.physe.2015.05.017.

Shin, S.W. et al. (2011). A study on the improved growth rate and morphology of chemically deposited $\mathrm{ZnS}$ thin film buffer layer for thin film solar cells in acidic medium. Solar Energy, 85(11), 2903-2911, doi:10.1016/j.solener.2011.08.030.

Talantikite-Touatia, D. et al. (2017). Effect of dopant concentration on structural and optical properties $\mathrm{Mn}$ doped ZnS films prepared by CBD method. Optik, 136, 362-367, http://dx.doi.org/doi:10.1016/j.ijleo.2017.02.032.

Tec-Yam, S. et al. (2012). High quality antireflective ZnS thin films prepared by chemical bath deposition. Materials Chemistry and Physics, 136, 386-393, http://dx.doi.org/ 10.1016/ j.matchemphys.2012.06.063.

Tobbeche, S. et al. (2019). Improvement of the CIGS solar cell performance: structure based on a ZnS buffer layer. Optical and Quantum Electronics, 51, 284, https://doi.org/10.1007/s11082019-2000-z.

Wang, Z. et al. (2017). Facile preparation of $\mathrm{ZnS} / \mathrm{CdS}$ core/shell nanotubes and their enhanced photocatalytic performance. International Journal of Hydrogen Energy, 42(27), 17394-17402, http://dx.doi.org/10.1016/j.ijhydene.2017.04.091.

Wei, A. et al. (2013). Preparation and characterization of $\mathrm{ZnS}$ thin films prepared by chemical bath deposition. Materials Science in Semiconductor Processing, 16, 1478-1484, http://dx. doi.org/10.1016/j.mssp.2013.03.016.

Wei, Z. et al. (2018). Synthesis and Luminescent Modulation of ZnS Crystallite by a Hydrothermal Method. ACS Omega, 3(1), 137-143, doi: 10.1021/acsomega.7b01574.

Woods-Robinson, R. et al. (2016). P-Type Transparent Cu-Alloyed ZnS Deposited at Room Temperature. Advanced Electronic Materials, 1500396, 1-9, doi: 10.1002/aelm.201500396.

Yang, K., Li, B. \& Zeng, G. (2019). Effects of temperature on properties of ZnS thin films deposited by pulsed laser deposition. Superlattices and Microstructures, 130, 409-415, https://doi.org/10.1016/j.spmi.2019.05.009.

Zhao, W. et al. (2017). Optical and magnetic properties of Co and Ni co-doped ZnS nanorods prepared by hydrothermal method. Journal of Alloys and Compounds, 698, 754-760, doi:10.1016/j.jallcom.2016.12.127. 